\title{
AC 2010-1738: ASSESSING ROLE ORIENTATION AMONG STEM RESEARCHERS: THE DEVELOPMENT OF A RESEARCH ROLE ORIENTATION INVENTORY
}

Michael Bowler, Michigan Technological University

Susie Amato-Henderson, Michigan Technological University

Tom Drummer, Michigan Technological University

Joseph Holles, Michigan Technological University

Joanna Schreiber, Michigan Technological University

Ted Lockhart, Michigan Technological University

Debra Charlesworth, Michigan Technological University

Jingfang Ren, Michigan Technological University 


\section{Assessing Role Orientation Among STEM Researchers: The Development of a Research Role Orientation Inventory}

\section{Introduction}

The concept of professional "roles" is a fundamental component in the study of the professions. ${ }^{1}$ Kultgen defines roles as "patterns of activity governed by generally shared expectations and performed by replaceable individuals" (pg. 38). ${ }^{1}$ Bebeau et al. suggests that a professional's role concept is "a dimension of motivation and commitment which influences the prioritization of professional over personal values" (pg. 32). ${ }^{2} \quad$ A role orientation inventory is a tool designed to assess one's professional role concept. Professional role concept is thus recognized as a key aspect in evaluating a person's understanding of and attitude toward the nature of their profession, the role of that profession in society and the constituencies the profession serves. As Bebeau notes, one's response to an ethical problem partially depends upon how he or she conceptualizes his or her role. ${ }^{2}$ For this reason, it is used extensively in the investigation of professional integrity and it has become central to the study of professional ethics in fields such as medicine, dentistry, law, and social work, and others. Within the last couple of decades, fieldspecific instruments for inventorying role orientation have been developed for the purpose of assessing an individual's level of professional integrity as well as for appraising educational programs designed to teach professional ethics.

For the past two decades there has been considerable scholarly disagreement concerning the nature of a profession and professionalism. ${ }^{1,3,4}$ A profession encompasses a notion broader than that of a specific functionary of the state, e.g., being a police officer or judge, although these may very well be and usually are considered professions. But it is also less narrow than just any haphazard group of individuals who happen to share some common interest, for instance, a chess club, or fulfill some social function, for example, a non-profit group dedicated to feeding the poor. Most, but not every conception of professionalism understand it to be a form of social institution. As a social institution, members of a profession are seen to play some beneficial role in society.

In this regard, the notion of playing a role is crucial to understanding what it is to be a professional. It indicates that a professional has duties and responsibilities that are associated with their role as a professional, responsibilities and obligations that do not apply to every member of the society. For example, imagine you were medical school dropout and someone came to your door complaining of severe headaches and dizziness. Even if you had the knowledge and means to treat the person, you would not be under the same obligation to help as one who is a professional doctor. We may fault you for not being a particularly caring human being - although these days perhaps you were just worried about a potential lawsuit or running afoul of state licensing requirements, but we would not accuse you of shirking your responsibilities as a doctor. The duties and responsibilities of a professional are typically articulated in a professional code of conduct. Moreover, because of the beneficial role that professionals provide to society they are typically afforded certain privileges. For example, doctors can prescribe medicine. 
Whether or not the role of a STEM (Science, Technology, Engineering, and Mathematics) researcher is deemed a profession depends upon how narrowly or broadly one circumscribes the nature of a profession. ${ }^{5,6}$ It is not our intent to take a position on this debate, instead we wish to motivate our adaptation of tools developed for professional ethics to STEM researchers and responsible conduct of research (RCR). As with other professions, STEM researchers are required to prioritize their professional and personal values. For this reason designing a role orientation tool to assess a STEM researchers' role concept will assist in understanding how they act when confronted by situations involving RCR principles. As Bebeau and Rest have argued, this is one component necessary for understanding ethical behavior. ${ }^{7,8}$

Therefore, an instrument for the purpose of inventorying the role orientation of STEM researchers would be important and quite useful. Such an instrument may help in understanding what motivates STEM researchers to abide by or violate the principles of RCR. For this reason, a research role orientation inventory should help those studying the nature of research integrity and those designing education programs in the responsible conduct of research. STEM researchers are held to ethical standards by funding agencies, the institutions they work for, professional societies and many of the journals in which they publish. This means that there could be severe consequences in an individual violates the principles of RCR. Our tool could be used to identify the relationship between one's research role concept and patterns of research misconduct for the purposes of preventing such misconduct through educational initiatives.

As part of an NSF sponsored project we have designed and tested such an instrument. In designing our instrument, we adapted the constructs of authority, responsibility, agency and autonomy from the original professional role orientation inventory (PROI) developed by Bebeau, Born, and Ozar ${ }^{2}$, which is a validated and reliable measure of role orientation for professionals and which has previously been adapted for a number of different professions. On the surface, these four components appeared to be legitimate elements (i.e., have face validity) of a STEM researcher's role concept, but part of our task was to validate this. Thus, our instrument was designed in part to measure those four constructs with regard to STEM researchers.

The construct of authority refers to a STEM researcher's attitude toward his or her expertise and knowledge. A STEM researcher with a strong sense of authority sees himself or herself as a good judge of outcomes and someone to whom others should defer in questions concerning his or her area of research. A STEM researcher with a weak sense of authority is more likely to defer to another's expert judgment, even when it contravenes their own.

Responsibility is defined as an individual's sense of commitment to others as a STEM researcher. This construct is designed to capture a researcher's awareness of the importance of the effects of his or her research on other people. A researcher with a strong sense of responsibility believes that his or her research must contribute to the welfare of others including those who are disadvantaged and the general public. On the other hand, at the opposite end of the spectrum, a researcher with a weak sense of responsibility tends to view the impact of their research on the general public as extraneous to his or her work.

Agency is intended to measure a STEM researcher's sense of control and power over his or her research. STEM researchers lacking a strong sense of agency regard themselves as powerless 
over his or her research. For example, one with a low sense of agency may feel unable to pursue research he or she thinks is important or may view himself or herself as incapable of securing research funding, etc. On the contrary, a researcher with a strong sense of agency would, for example, believe themselves capable of being an excellent researcher, of acquiring the means and opportunities necessary to achieve his or her research goals, and effective at managing research projects.

Autonomy registers the extent to which a STEM researcher is comfortable with acting independently in his or her research. A researcher with a strong sense of autonomy is comfortable making decisions about his or her research and acting on those decisions without the approval or consent of others. On the other hand, a researcher with a low sense of autonomy feels most comfortable making decisions and taking action with the approval and consent of others. He or she would probably seek consensus prior to making decisions when working with a team of researchers.

In addition, we have also identified and included in our instrument a fifth component that we believe is essential for understanding an individual's attitude toward the role of STEM researcher, namely, one's sense of duty to fundamental and absolute values and principles. Specifically, the newly added construct of duty refers to the breadth of a researcher's commitment to absolute principles and values, i.e., principles and values that should not be sacrificed regardless of the cost or benefit that may accrue to oneself or others by doing so. This latter is what differentiates duty from responsibility, insofar as responsibility measures one's commitments to self or others. Duty implies that one is obligated to act in a certain manner, regardless of the consequences. A researcher with a strong sense of duty believes that there are absolute principles and values related to STEM research and feels obligated to follow those principles and realize those values regardless of the consequences. A researcher with a weak sense of duty views the nature of their research and their research conduct through a "costbenefits" lens and is motivated accordingly. For example, this construct would measure one's duty to extend the frontiers of scientific and engineering knowledge, and maintaining one's integrity in the proposing, carrying out and publication of STEM research, etc. This is a significant addition to the original PROI and represents the fact that, unlike those professions whose end product consists of serving a client or patient, STEM researchers may very likely understand their role as serving the abstract principles and values of science and the scientific method in addition to (or even above) whatever social or personal benefits their research may provide.

Ultimately, our task is to design an instrument that could assess role orientation among STEM researchers with respect to the five mentioned constructs. However, an essential part of this task is to test the reliability and validity of each of these constructs as applied to STEM research. Thus, we are open to the possibility that one or more of these constructs may not be a reliable or valid element of STEM researcher's role concept. Moreover, the full process of examining the instrument for reliability and validity may point toward other possible, heretofore unknown, elements of the role concept of STEM researchers.

In this paper, we describe the design of our instrument and examine the results of our pilot study among a multi-national body of STEM graduate students. We also discuss possible applications 
of our instrument to the study of research integrity and for the assessment of pedagogical approaches to responsible conduct of research.

\section{Method}

\section{Inventory Development}

Our multidisciplinary team of researchers utilized a modified Delphi approach to identify statements that could be used to measure the constructs of authority, responsibility, autonomy, agency and duty. First, we identified those PROI items ${ }^{2}$ that were adaptable for use in measuring a researcher's role orientation along the original four constructs. For example, one original PROI item designed to measure a dentist's sense of professional authority states "A patient who questions my recommendations should feel comfortable asking another colleague for his/her interpretation". Our team adapted this statement resulting in three new potential items to measure a researcher's sense of authority: 1) "A supervisor who questions my recommendations regarding research should feel comfortable asking another colleague for his or her interpretation."; 2) "When interpreting research results, no one should question the lead researcher's authority"; and 3) "The sponsor of my research should feel comfortable asking another colleague to interpret my data." This process of adaptation resulted in the generation of $10-15$ items per construct.

Next, our research team individually brainstormed other possible statements that could be useful in measuring the constructs. Experience, a review of field specific literatures, analysis of discipline-specific organizations' materials related to the role of a researcher, discussion with colleagues, and other research-related resources contributed to the resulting 10 to 25 items per construct. Thus, having at least 20 adapted and brainstormed statements designed to measure each of the constructs, we next proceeded to ensure clarity of the items.

To determine clarity, the research team provided their colleagues with a draft of the items within one of the 5 constructs, in addition to a brief description of the construct which included a definition. Feedback from colleagues was brought forward during several research team meetings in which we evaluated the clarity and cross-disciplinary appropriateness of each item within each of the 5 constructs. This process of consensus resulted in minor "word-smithing", major overhauling, deletion of items, and the addition of new items to the list of possible statements. The resulting items were chosen based upon the consensus that they were, in fact, indicative of one of the constructs (some items were inadvertently applicable to several constructs, and were thus deleted) and were equally applicable across disciplines. In addition, we sought to narrow the list of items down to approximately 30 items representing each construct. The final instrument contained 143 items. Table 1 contains example items included in the inventory designed to measure each construct.

In addition to the cross-disciplinary appropriateness of the constructs and items used in the instrument there is also the important issue of whether these constructs and items are appropriate across cultures. Key to mitigating cultural bias is insuring a sufficiently diverse pool of respondents. If certain constructs and items were sensitive to cultural differences this would tend to reduce the reliability measure of these items and constructs. Therefore, in the analysis and 
redesign of the tool, care will be taken to investigate the possibility of cultural bias among elements of the tool. On the same account, if certain items and constructs exhibit a high reliability among a culturally diverse pool of respondents this would strongly indicate that these are not sensitive to cultural differences.

Table 1. Role Orientation Constructs and Example Inventory Items

\begin{tabular}{|c|c|}
\hline Construct & Example Inventory Items \\
\hline Agency & $\begin{array}{l}\text { - I believe that competition for research funds would make it } \\
\text { difficult for me to pursue important research. } \\
\text { - I feel that I have the ability to control my own destiny, to effect } \\
\text { significant changes in my research discipline, and to play an active } \\
\text { role in making things happen. }\end{array}$ \\
\hline Authority & $\begin{array}{l}\text { - Researchers are the best suited to regulate and enforce } \\
\text { responsible conduct of research in their discipline. } \\
\text { - Generally speaking, I do not need feedback from my peers to help } \\
\text { me with my research. }\end{array}$ \\
\hline Responsibility & $\begin{array}{l}\text { - Because I am a professional, I shoulder some responsibility for the } \\
\text { misperceptions that result from poor work generated by my } \\
\text { discipline. } \\
\text { - If the research of a scientist or engineer will likely have a negative } \\
\text { impact on society, he or she should discontinue that research. }\end{array}$ \\
\hline Autonomy & $\begin{array}{l}\text { - I do not require the approval of my peers in order to feel confident } \\
\text { conducting my research in the way that I see fit. } \\
\text { - It is important to take into account public opinion regarding the } \\
\text { value of various research projects when choosing which to pursue. }\end{array}$ \\
\hline Duty & $\begin{array}{l}\text { - A researcher is never justified in manipulating data even if doing so } \\
\text { would further research that will lead to significant social benefits, } \\
\text { e.g., curing cancer. } \\
\text { - Science and engineering research is valuable for its own sake } \\
\text { regardless of whatever personal or public benefits it may have. }\end{array}$ \\
\hline
\end{tabular}

Given the large nature of the inventory (143 items), we split each construct among two different versions of the inventory. Each version contained approximately 71 items unique to that version, along with an additional 20 items from the other version (to rule out differences due to samples). Participants were asked to rate their level of agreement to each statement on a 6-point Likerttype scale ranging from strongly disagree to strongly agree. They were also given the option of selecting the response "I do not fully understand the statement." They were instructed to respond to each statement as though they were an active faculty researcher.

\section{Pilot Study}

We pilot tested our inventory using students who had applied to and been accepted into graduate programs at Michigan Technological University. A solicitation email was sent to personal 
and/or school-related email accounts provided by all accepted students $(n=740)$.

Approximately 90 graduate-level students provided at least a partial response to each version, which equated to a response rate of about $25 \%$ after accounting for "bounced" email solicitations. Despite our attempt to minimize the length of the inventory by creating two versions, a large rate of partial responses resulted nonetheless.

\section{Reliability Analysis}

Our goal was to produce a final inventory with high internal consistency that contained roughly eight items per construct. As described above, the original survey instrument contained 143 items and was split into two instruments, with some questions common to both instruments. We compared the response distributions to these common questions to test for an order effect and for any differences between samples. We treated the Likert scale data as continuous and used Cronbach's alpha $(\alpha)^{2}$ as the measure of internal reliability. Nunnally and Bernstein ${ }^{9}$ discuss acceptable values of alpha and regard values $>0.70$ as satisfactory. We used only complete data cases in these analyses. In the first round of analyses we used all items for each construct in the analyses and proceeded to eliminate items that were poorly correlated with the total construct score.

\section{Results}

We obtained $n=90$ and $n=58$ responses to the two versions of the instrument, but there was substantial missing data. For those questions common to both parts we observed little variability in response distributions. We limited our analysis to the items contained in the version with $\mathrm{n}=$ 90 to maximize sample size, although an acceptable number of items was available.

Reliability values varied across the constructs with the lowest reliability for the Autonomy construct. Elimination of items with low correlations increased reliability to acceptable levels with the exception of the Autonomy construct $(\alpha=0.48$, see Table 2$)$. Also, the Agency construct was just slightly below meeting the Cronbach alpha reliability measure of .70. As the number of items was reduced the sample size increased, so a change in $\alpha$ could be due to a change in the sample size and the particular set of responses included in the analysis.

Table 2. Reliability analysis of five constructs on proposed instrument

\begin{tabular}{|c|c|c|c|}
\hline Construct & Number of Items & Sample Size* & Cronbach's $\alpha^{*}$ \\
\hline Agency & $19(12)$ & $26(33)$ & $\mathbf{0 . 5 6}(\mathbf{0 . 6 7})$ \\
\hline Authority & $22(15)$ & $32(36)$ & $0.62(0.75)$ \\
\hline Responsibility & $16(13)$ & $28(32)$ & $0.73(0.74)$ \\
\hline Autonomy & $15(12)$ & $29(29)$ & $0.39(0.48)$ \\
\hline Duty & $19(15)$ & $27(29)$ & $0.68(0.79)$ \\
\hline
\end{tabular}

*Sample sizes are the number of complete cases from $n=90$ responses. Results in () are from the reduced instrument. 
Four of five constructs exhibited acceptable levels of internal consistency, but the small sample sizes relative to the number of items raises concern about the adequacy of these analyses. A second pilot study using the reduced number of items will be conducted to help derive a final version of the instrument.

\section{$\underline{\text { IV. Discussion }}$}

Our pilot data and analysis support the existence of four of the five constructs in the assessment of role orientation among STEM researchers. The constructs of responsibility, authority, agency and duty had acceptable levels of reliability for this pilot study. Given our pilot findings, the construct of autonomy did not exhibit levels of internal consistency. This may be due to small sample size, invalid inventory items designed to measure the construct, or the lack of its presence in the role orientation of STEM researchers. Examining the existence of this construct, along with improved validation of the others, is the focus of ongoing follow-up work.

Perhaps the most significant finding from our pilot study is that the construct of duty that we postulated and which has not been a component of other adaptations of the PROI turned out to be the most reliable construct in the reduced instrument (see Table $1, \alpha=0.79$ ). This is important because it indicates that the notion of duty may be an essential, and perhaps the most consistent component, of a STEM researcher's orientation toward their role. Therefore, our pilot analysis has confirmed the need to retain this construct in our final instrument. In a time when STEM research is increasingly being viewed as serving some client or other, whether it be government, private industry, a university, the public at large, or even the researcher's own personal selfaggrandizement, it is important to be able to measure STEM researchers commitment to the absolute principles and values of science in relation to their commitment to benefit themselves and/or others. In all likelihood this aspect of a researcher's role orientation makes a difference as to whether they will abide by the principles of responsible conduct of research even in the face of the possibility of reaping attractive, and in certain cases noble, benefits from not doing so.

Once fully validated and tested, our tool should provide researchers with the ability to distinguish and differentiate the role orientation that STEM researchers bring to their discipline from that of other disciplines such as dentistry, medicine, law, social work, etc. In the future this may provide us with valuable information about the similarities and differences that exist between STEM researchers and those who belong to recognized professions. This is an important topic to be investigated because a substantial amount of work and effort has been put into both the practice and study of professionalization and how this is related to professional behavior and ethics. Building a bridge between STEM researchers and recognized professionals will be of benefit both to those who study RCR and RCR educators, since it will help them to adapt the tools already available to professional ethics educators and researchers to STEM researchers. We believe that our tool represents a first, but very important step, in building this bridge.

More specifically, our tool should also afford us the ability to differentiate between role orientations among the different disciplines within STEM. Perhaps the most general distinction in this regard is between those studying science and mathematics and those studying engineering and technology. In either case, we are concerned with researchers searching for knowledge. Yet 
engineering and technology and the research that accompanies it serves in the final analysis to promote human's ability to technically master their environment ideally for the common good. Traditionally, the research of scientists and mathematicians are seen to serve in the final analysis the acquisition of knowledge for its own sake. Will this difference manifest itself as a difference in role orientation? For instance, will it be the case that engineers tend to score higher on responsibility and lower on duty than scientists and vice-versa? Of course, only empirical work will demonstrate whether this is accurate or not. Our final tool will make this work and research like it possible.

Additionally, the tool we have designed can help to identify variations in STEM researcher role orientation among national and multi-national STEM researchers and graduate students. This may allow for a better and more complete understanding of attitudinal or behavioral differences among STEM researchers and graduate students from different countries and of different nationalities. This in turn could help identify sources of conflict or misunderstanding between international STEM researchers and graduate students, on the one hand, and American expectations regarding standards of responsible conduct of research, on the other hand.

There are a number of possible pedagogical applications of this instrument as well. For instance, it could be used to assess the impact of educational programs on student's understanding of the role of a STEM researcher and, in fact, whether or not it is possible to modify role orientation by means of educational initiatives. Perhaps role orientation is a stable characteristic. If it is possible to modify role orientation through pedagogical interventions then this could be a significant advance in ethics education in science and engineering. For example, if an educational program could make STEM researchers or graduate students more "dutiful" in their role, then one suspects that this will help motivate them to abide by the principles of responsible conduct of research when faced with temptations to engage in research misconduct. Or, along a slightly different track, if a young researcher or graduate student happens to have a relatively low sense of agency and autonomy that person may benefit from some added mentoring. These are only two examples of many possible applications of the tool we have designed.

\section{$\underline{\text { V. Conclusion }}$}

In conclusion, we have shown that our instrument reliably measures four out of the five STEM researcher role orientation constructs that it was designed to measure, namely, agency, authority, responsibility, and duty. The last is most significant since this confirms our hypothesis that duty is an important component of STEM researcher's role orientation. We are in the process of doing more pilot work in order to further validate our tool and to examine more fully the construct of autonomy and to decide whether or not it belongs in the instrument.

\section{Acknowledgements:}

The authors gratefully acknowledge financial support from the Ethics Education in Science and Engineering program, Division of Social and Economic Sciences, Directorate for Social, Behavioral \& Economic Systems of the National Science Foundation through grant \#0832922. 


\section{$\underline{\text { References }}$}

1. Kultgen, J. (1988). Ethics and Professionalism (Philadelphia: University of Pennsylvania Press).

2. Bebeau, M. J., Born, D. O., Ozar, D. T. (1993). "The Development of a Professional Role Orientation Inventory," Journal of the American College of Dentists, 60(2), 27 - 33.

3. Ozar, D. (1985). "Three Models of Professionalism and Professional Obligation in Dentistry," Journal of the American Dental Association 110, 173 - 177.Cronbach, L. J. (1951). "Coefficient alpha and the internal structure of tests," Psychometrika, 16(3), 297-334.

4. Davis, M. (1999). "Professional Responsibility: Just Following the Rules?" Business and Professional Ethics Journal 18(1), 65 - 87.

5. Davis, M. (1995). “After Such Knowledge, What Responsibility?” Professional Ethics 4(1), 49-74.

6. Davis, M. (2003). "What's Philosophically Interesting about Engineering Ethics?” Science and Engineering Ethics, 9(3), 353 - 361.

7. Rest, J. (1983) Morality. In: Mussen PH (series ed.) and Flavell J, Markman E (vol. eds.). Handbook of Child Psychology, Vol. 3, Cognitive Development, $4^{\text {th }}$ ed. New York, NY: Wiley, 556-629.

8. Rest, J., Narváez, D, Bebeau, MJ, Thoma, SJ (1999). Postconventional Moral Thinking: A NeoKohlbergian Approach. Hillsdale, NJ: L. Earlbaum Associates.

9. Nunnally, J. and I. Bersntein (1994). Psychometric Theory ( ${ }^{\text {rd }}$ edition) (New York: McGraw Hill). 